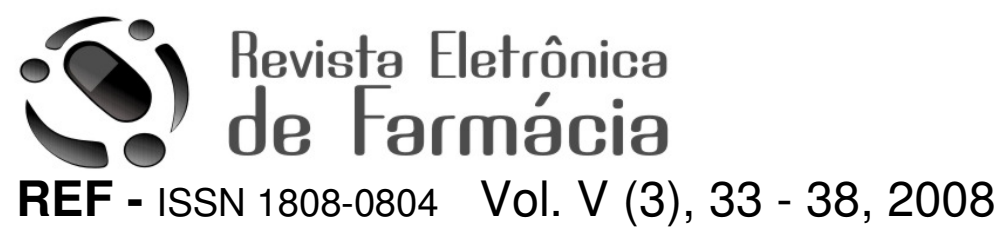

\title{
CONTROLE DE QUALIDADE DO ÁCIDO TÂNICO DE ALGUMAS FARMÁCIAS DE MANIPULAÇÃO DE CAMPO GRANDE (MS), BRASIL
}

\author{
Quality control of tannic acid from some pharmacies \\ of campo grande city (ms), Brazil
}

\author{
Luiz Fabrício Gardini Brandão', Carolina Marien Duarte da Costa1, \\ Danielle Pérsio Lacerda ${ }^{1}$ e João Máximo de Siqueira ${ }^{2}$ \\ ${ }^{1}$ Universidade Federal de Mato Grosso do Sul. \\ 'Laboratório de Produtos Naturais, Campus Centro-Oeste Dona Lindú, \\ Universidade Federal de São João Del Rei, Divinópolis, MG.
}

*autor para correspondência: jmaximo.siqueira@gmail.com

Recebido em 14/01/2008 - Aceito em 09/06/2008

\begin{abstract}
RESUMO: Os taninos são substâncias fenólicas que apresentam diversas atividades farmacológicas. Dentre elas, destacam-se atividades antimutagênicas, anticarcinogênicas, antioxidante e bactericida. $O$ ácido tânico, que pertence à classe dos galotaninos, é indicado para infecções causadas por herpes labial ou para uso ginecológico devido à sua ação adstringente. O propósito deste trabalho foi investigar a qualidade do ácido tânico vendido em farmácias de Campo Grande (MS). As quatro amostras analisadas por métodos qualitativos e físicoquímicos foram comparadas à luz do padrão Merck. Os testes resumiram-se em caracterizações organolépticas, reações de complexação, reações de precipitação e análise por cromatografia em camada delgada. Em todos os testes realizados observou-se que o padrão apresentou sempre resultados positivos quanto à sua qualidade enquanto que as amostras apresentaram resultados negativos. Foi possível concluir que todas as amostras analisadas não atingiram satisfatoriamente o padrão Merck de qualidade.
\end{abstract}

PALAVRAS-CHAVES: ácido tânico, taninos, adstringente, qualidade

\begin{abstract}
Tannins are phenolic substances that present different pharmacological activities such as antimutagenic, anticarcinogenic, antioxidant and bactericidal. Tannic acid belongs to the class of galotannins and is indicated for herpes lips infection and gynecological use because of its astringent properties. Assays were performed to investigate the quality of the tannic acid sold in Campo Grande, MS pharmacies. Four samples were analyzed through qualitative and physical-chemical methods and compared with a pattern manufactured by Merck industry. The performed tests were organoleptic characterization, complexation and precipitation reactions, and thin layer chromatography analysis. All the tests performed showed positive results for the pattern quality and negative results for the sample quality. It was plausible to conclude that all samples did not achieve satisfactorily the Merck pattern.
\end{abstract}

KEYWORDS: tannic acid, tannins, astringent, quality

\section{INTRODUÇÃO}

Os taninos são substâncias fenólicas amplamente distribuídas em alimentos e bebidas. Esta classe de compostos possui a habilidade de formar complexos insolúveis, em água, com alcalóides, gelatina e outras proteínas. Estes compostos possuem importantes características gustativas responsáveis pela adstringência de muitos frutos e produtos vegetais a exemplo de vinhos, sucos de frutas, chás e outras bebidas (SIMÕES et al., 2004). Estudos feitos por Haslam mostram que as atividades farmacológicas dos taninos são proporcionadas por sua capacidade de complexar com íons metálicos, como o cobre (KRAAL et al, 2006) e o ferro (ANDRADE Jr et al, 2006), de ser antioxidante e de complexar com macromoléculas como proteínas e polissacarídeos (HASLAM, 1996 e 1998). Outro estudo que mostra a diversidade da atividade biológica e estrutural dos taninos foi realizado 
Brandão, L. F. G. et al./Revista Eletrônica de Farmácia Vol 5(3), 33 - 38, 2008.

por De Bruyne e colaboradores (DE BRUYNE et al, 1999). Devido a sua reatividade, certos taninos são farmacologicamente e economicamente importantes (BALANDRIN et al, 1985; CHUNG et al, 1988; KHANBABAEE \& VAN REE, 2001; OKUDA, 2005, apud HALVORSON \& GONZALEZ, 2008). A complexação entre taninos e proteínas é a base para suas propriedades. Exemplos disso podem ser observados na aplicação desta reação no controle de insetos, fungos, bactérias e para seus principais usos industriais, como manufatura do couro, tinta, corantes, clareamento de cerveja e vinho.

A classe dos taninos é dividida em taninos hidrolisáveis e condensados. Ácido tânico é a forma mais simples de tanino hidrolisável. Estudos realizados nos últimos anos comprovam a importância do ácido tânico como um agente antioxidante (CHOI et al., 2006), antimutagênico (CHEN \& CHUNG, 2000), anticarcinogênico (NEPKA et al, 1999), além de possuir efeitos inibitórios nas enzimas do citocromo P450 (YAO et al, 2008). Há estudos, in vivo, que comprovam também o aumento da excreção de gordura, proteína e água nas fezes de ratos que tiveram ácido tânico administrado (BRAVO et al., 1994), assim como inibição da proliferação de colangiócitos (TAFFETANI et al, 2005). Outro estudo demonstra que o ácido tânico reduz a hepatotoxicidade e a genotoxicidade causada pela zidovudina que é um dos principais medicamentos inibidores da enzima transcriptase reversa utilizado por pacientes HIV positivos (TIKOO et al, 2008).

O ácido tânico é utilizado em farmácias de manipulação para uso tópico devido as suas propriedades adstringente e antimicrobiana, sendo inserido em formulações magistrais indicada para infecções causadas por herpes labial ou formulações para uso ginecológico (MEMENTO TERAPEUTICO, 2002). Curiosamente, ambas as formulações possuem como coadjuvante o alúmen de potássio, substância incompatível com os taninos, pois ocorre precipitação.

O presente estudo procura investigar a qualidade do ácido tânico vendido pelas farmácias de manipulação de Campo Grande (MS), através de análises organolépticas, reações de precipitação e avaliação por cromatografia em camada delgada.

\section{MÉTODOS}

As amostras submetidas a análises foram adquiridas em Campo Grande e identificadas como A, B, C, D e o padrão Merck de tanino (ácido tânico) como P.

\section{Preparo das Amostras}

Para os testes de reação de complexação com cloreto férrico e reação de precipitação com gelatina, $300 \mathrm{mg}$ de cada amostra foi solubilizado em $1,5 \mathrm{~mL}$ de água. Na cromatografia em camada delgada, pesou-se 10,0mg das amostras que foi solubilizada em 2,0mL de solvente acetona : água (3:1).

\section{Preparo do Padrão}

Para os testes de reação de complexação com cloreto férrico e reação de precipitação com gelatina, o padrão foi preparado da mesma forma que as amostras. No entanto, para a análise cromatográfica, 1,0mg do padrão foi solubilizado em 1,0mL de acetona : água (1:1).

\section{Preparo da Placa Cromatográfica e do Eluente}

A placa cromatográfica foi preparada utilizando uma chapa de vidro $20 \mathrm{~cm} \times 20 \mathrm{~cm}, 5 \mathrm{~g}$ de sílica gel $60 \mathrm{G}$ da marca Merck e $20 \mathrm{~mL}$ de água. Após secar naturalmente a sílica sobre a placa, esta foi ativada em estufa à $100^{\circ}$ C por uma hora. O eluente utilizado foi água : acetato de etila : ácido fórmico (1:8:1).

\section{Caracterização Organoléptica} padrão.

Para a caracterização organoléptica, observou-se a cor, o odor, o sabor e o aspecto das amostras e do

\section{Reação de Complexação com Cloreto Férrico}

Em tubos de ensaio foi adicionado às amostras e ao padrão preparado $0,1 \mathrm{~mL}$ de solução de cloreto férrico $5 \%$.

\section{Reação de Precipitação com Gelatina}

O padrão e as amostras foram colocados em um tubo de ensaio para reagir com 3,0 mL de solução de gelatina comercial $(1 \mathrm{~g} / \mathrm{L})$.

\section{Cromatografia em Camada Delgada}

Com o auxílio de uma micropipeta foram aplicados 14 pontos na placa cromatográfica. A tabela 1 mostra o volume e a massa correspondente das amostras e do padrão aplicado.

Tabela 1: Massa e volume da amostra e do padrão aplicado na placa cromatográfica:

\begin{tabular}{cccc}
\hline Aplicação & Amostra/Padrão & Volume $(\mu \mathrm{L})$ & Massa $(\mu \mathrm{g})$ \\
\hline 01 & A & 10 & 50 \\
02 & A & 5 & 25 \\
03 & B & 10 & 50 \\
04 & B & 5 & 25 \\
05 & C & 10 & 50 \\
06 & C & 5 & 25 \\
07 & D & 10 & 50 \\
08 & D & 5 & 25
\end{tabular}


Brandão, L. F. G. et al./Revista Eletrônica de Farmácia Vol 5(3), 33 - 38, 2008.

\begin{tabular}{cccc}
09 & $\mathrm{P}$ & 10 & 10 \\
10 & $\mathrm{P}$ & 5 & 5 \\
11 & $\mathrm{P}$ & 4 & 4 \\
12 & $\mathrm{P}$ & 3 & 3 \\
13 & $\mathrm{P}$ & 2 & 2 \\
14 & $\mathrm{P}$ & 1 & 1 \\
\hline
\end{tabular}

Após aplicação, a placa foi colocada em uma cuba cromatográfica em contato com o eluente. Ao terminar a eluição, a placa foi revelada com solução de cloreto férrico $5 \%$.

\section{RESULTADOS E DISCUSSÃO}

\section{Caracterização Organoléptica}

As características organolépticas observadas estão descritas na tabela 2 e o aspecto do padrão e amostra A estão na figura 1.

Tabela 2: Características organolépticas das amostras e do padrão.

\begin{tabular}{|c|c|c|c|c|}
\hline Amostra/Padrão & Cor & Odor & Sabor & Aspecto \\
\hline 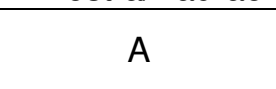 & $\begin{array}{c}\text { Castanho } \\
\text { Escuro }\end{array}$ & Fraco & Adstringente & Pó leve, Amorfo \\
\hline B & $\begin{array}{l}\text { Castanho } \\
\text { Escuro }\end{array}$ & Amadeirado & Adstringente & Pó leve, Amorfo \\
\hline C & Castanho Claro & Amadeirado & Adstringente & Pó leve, Amorfo \\
\hline D & $\begin{array}{c}\text { Castanho } \\
\text { Escuro }\end{array}$ & Amadeirado & Adstringente & Pó leve, Amorfo \\
\hline $\mathrm{P}$ & Amarelado claro & Fraco & $\begin{array}{l}\text { Fortemente } \\
\text { Adstringente }\end{array}$ & Pó leve, Amorfo \\
\hline
\end{tabular}

Figura 1: Aspecto visual do padrão e da amostra $A$.

$(\mathbf{P}=$ padrão; $\mathbf{A}=$ amostra $\mathbf{A})$

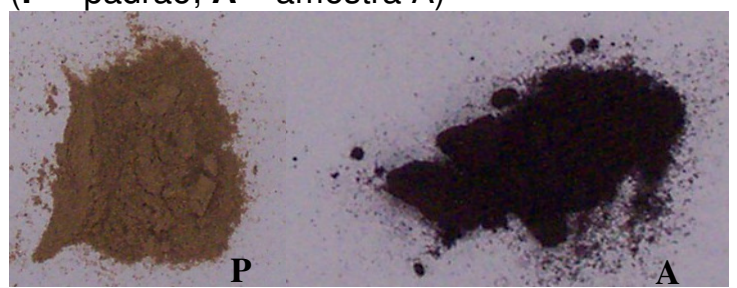

\section{Reação de Complexação com Cloreto Férrico}

A complexação do ácido tânico com o cloreto férrico resulta em um precipitado de coloração azulacinzentada como ocorreu com o padrão. No entanto, as amostras analisadas apresentaram um precipitado de cor castanho claro como mostra a figura 2.

Figura 2: Reação de complexação com cloreto férrico ( $\mathbf{P}=$ padrão; $\mathbf{1}=$ amostra $A ; \mathbf{2}=$ amostra $B ; \mathbf{3}=$ amostra $C ; \mathbf{4}=$ amostra $D)$

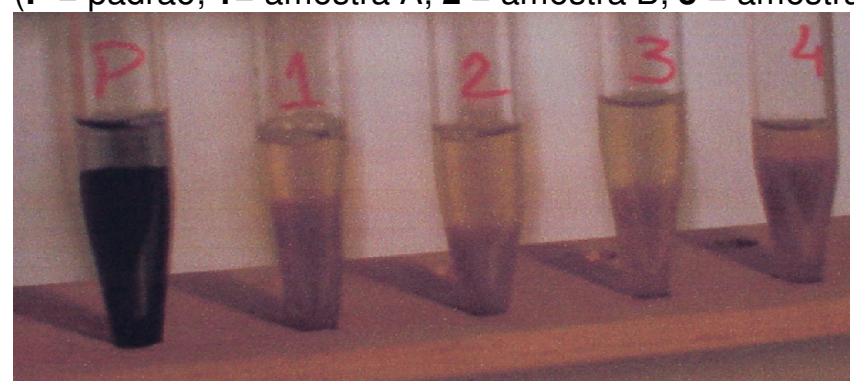

\section{Reação de Precipitação com Gelatina}

O padrão apresentou um precipitado de coloração branco amarelado enquanto que as amostras analisadas formaram um leve precipitado castanho avermelhado como mostra a figura 3. 
Brandão, L. F. G. et al./Revista Eletrônica de Farmácia Vol 5(3), 33 - 38, 2008.

Figura 3: Reação de precipitação com gelatina

( $\mathbf{B}=$ branco; $\mathbf{P}=$ padrão; $\mathbf{1}=$ amostra $A ; \mathbf{2}=\operatorname{amostra} B ; \mathbf{3}=$ amostra $C ; \mathbf{4}=$ amostra $D$ )

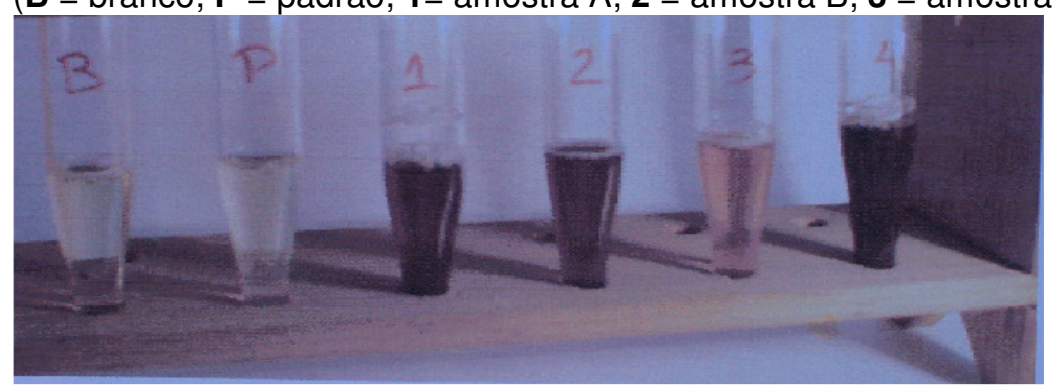

Cromatografia em Camada Delgada

A comparação do perfil cromatográfico revelou-se positiva somente para o padrão em suas diferentes concentrações e não foi detectada a presença de ácido tânico em nenhumas das amostras por este método, mesmo em concentrações cinco vezes maiores que ao do padrão, como mostra a figura 4.

Figura 4: Cromatografia em camada delgada

$\left(\mathbf{A}_{50}, \mathbf{B}_{50}, \mathbf{C}_{50}\right.$ e $\mathbf{D}_{50}$ são aplicações de $50 \mu \mathrm{g}$ das amostras; $\mathbf{A}_{25}, \mathbf{B}_{25}, \mathbf{C}_{25}$ e $\mathbf{D}_{25}$ são aplicações de $25 \mu \mathrm{g}$ das amostras; $\mathbf{P}_{10}, \mathbf{P}_{5}, \mathbf{P}_{4}, \mathbf{P}_{3}, \mathbf{P}_{\mathbf{2}}, \mathbf{P}_{\mathbf{1}}$ são aplicações de $10,5,4,3,2,1 \mu \mathrm{g}$ respectivamente do padrão)

$\begin{array}{lllllllllllllllllllll}A_{50} & A_{25} & B_{50} & B_{25} & C_{50} & C_{25} & D_{50} & D_{25} & P_{10} & P_{5} & P_{4} & P_{3} & P_{2} & P_{1}\end{array}$

\section{CONCLUSÃO}

O presente trabalho visa avaliar a qualidade de amostras de ácido tânico presentes no mercado farmacêutico de Campo Grande, MS, tendo como orientação os dados disponíveis na literatura sobre este produto na literatura farmacêutica (MERCK, 2006, FARMACOPEIA PORTUGUESA 2002) e, principalmente, as exigências da legislação da ANVISA (ANVISA, 2004), bem como o definido pela WHO (WHO, 1992). Pelo que se pôde observar no resultado apresentado, as amostras de ácido tânico avaliadas no presente trabalho estão comprometidas na capacidade de complexação e adstringência, propriedades que comprometem a atividade farmacológica dos taninos, pois esta relaciona-se, de uma maneira geral, ao seu mecanismo de ação (SCALBERT, 1991). Essa constatação pôde ser imediatamente observada, quando se comprova a qualidade do tanino avaliado com o aspecto físico visualizado pelo padrão (Figura 1), sendo este ultimo de acordo com o descrito na Farmacopéia e Merck (FARMACOPEIA PORTUGUESA, 2002; MERCK 2006), ou seja, a coloração avermelhada presente nos taninos é típica de taninos que sofreram acoplamento oxidativo. Uma simples avaliação farmacêutica, desenvolvido em aulas praticas de farmacognosia, controle de qualidade na academia, oferece suporte suficiente para a constatação da qualidade deste produto presente em farmácias comerciais e este tipo de atividade vai de encontro as denominadas "atividades reais" preconizada para o ensino farmacêutico.

\section{REFERÊNCIAS}

ANDRADE Jr, R.G.; GINANI, J.S.; LOPES, G.K.B.; DUTRA, F.; ALONSO, A.; HERMES-LIMA, M. Tannic acid inhibits in vitro iron-dependent free radical formation. Biochimie. v. 88, p. 1287-1296, 2006.

ANVISA 2004. Agência Nacional de Vigilância Sanitária, Brasil, Leis, decretos, etc. Resolução 48, de 16 de março de 2004. Dispõe sobre o registro de medicamentos fitoterapicos. Diário Oficial da Republica Federativa do Brasil, Brasília. 
Brandão, L. F. G. et al./Revista Eletrônica de Farmácia Vol 5(3), 33 - 38, 2008.

BALANDRIN, M. F.; KLOCKE, J.A.; WORTELE, E.S.; BOLLINGER, W.H. Natural plant chemicals: sources of industrial and medicinal materials. Science. v. 228, p. 1154-1160, 1985.

BRAVO, L.; ABIA, R.; EASTWOOD, M.A.; SAUCRA-CALIXTO, F. Degradation of polyphenols (catechin and tannic acid) in the rat intestinal tract. Effect on colonic fermentation and faecal output. British Journal of Nutrition. v.71, p. 933-946, 1994.

CHEN, S.C.; CHUNG, K.T. Mutagenicity and antimutagenicity studies of tannic acid and its related compounds. Food and Chemical Toxicology. v. 38, n. 1, p. 1-5, 2000.

CHOI, J.M.; HAN, J.; YOON, B.S. Antioxidant properties of tannic acid and its inhibitory effects on paraquatinduced oxidative stress in mice. Food Science and Biotechnology. v. 15, n. 5, p. 728-734, 2006.

CHUNG, K.; WONG, T.; WEI, C.; HUANG, Y.; LIN, Y. Tannins and human health: a review. Critical Reviews in Food Science and Nutrition. v. 38, p. 421-464, 1998.

DE BRUYNE, T.; PIETERS, L.; DEELSTRA, H.; VLIETINCK, A. Condensed vegetable tannins: biodiversity in structure and biological activities. Biochemical Systematics and Ecology. v. 27, p. 445-459, 1999.

FARMACOPEIA PORTUGUESA VII, 2002.

HALVORSON, J.J.; GONZALEZ, J.M. Tannic acid reduces recovery of water-soluble carbon and nitrogen from soil and affects de composition of Bradford-reactive soil protein. Soil Biology and Biochemistry. v.40, p. 186-197, 2008.

HASLAM, E. Natural polyphenols (vegetable tannins) are drugs and medicines: possible modes of action. Journal of Natural Products. v. 59, p. 205-215, 1996.

HASLAM, E. Pratical polyphenols - from structure to molecular recognition and physiological action. Cambridge: Cambridge University. v. 321, 1998.

KHANBABAEE, K.; VAN REE, T. Tannins: classification and definition. Natural Products Reports. v. 18, p. 641649, 2001.

KRAAL, P.; JANSEN, B.; NIEROP, K.G.J.; VERSTRATEN, J.M. Copper complexation of tannic acid in aqueous solution. Chemosphere. v. 65, p. 2193-2198, 2006.

MEMENTO TERAPÊUTICO PROGRAMA DE FITOTERAPIA, edição 2002, Prefeitura da Cidade do Rio de Janeiro. Disponível eletronicamente (Capturado em Janeiro/2008)

http://www.saude.rio.rj.gov.br/cgi/public/cgilua.exe/web/templates/htm/v2/view.htm?infoid=2912\&editionsectionid= 37.

MERCK INDEX, FOURTEENTH EDITION, MERCK \& CO., INC, NEW JERSEY, 2006.

NEPKA, C.; SIVRIDIS, E.; ANTONOGLOU, O.; KORTSARIS, A.; GEORGELLIS, A.; TAITZOGLOU, I.; HYTIROGLOU, P.; PAPADIMITROU, P.; ZINTZARAS, I.; KOURETAS, D. Chemopreventive activity of very low dose dietary tannic acid administration in hepatoma bearing $\mathrm{C} 3 \mathrm{H}$ male mice. Cancer Letters. v. 141, p. 57-62, 1999.

SCALBERT, A. Antimicrobial properties of tannins. Phytochemistry. v. 30, p. 3875-83, 1991.

SIMÕES, C.M.O.; et al. Farmacognosia: Da planta ao medicamento. 5ª Edição. Porto Alegre/Florianópolis: UFRGS, 2004.

TAFFETANI, S.; UENO, Y.; MENG, F.; VENTER, J.; FRANCIS, H.; GLASER, S.; ALPINI, G.; PATEL, T. Tannic acid inhibits cholangiocyte proliferation after bile duct ligation via a cyclic adenosine 5', 3' monophosfatasedependent pathway. American Journal of Pathology. v.166, n. 6, p. 1671-1679, 2005.

TIKOO, K.; TAMTA, A.; ALI, I.Y.; GUPTA, J.; GAIKWAD, A.B. Tannic acid preventes Azidothymidine (AZT) induced hepatotoxicity and genotoxicity along with change in expression of PARG and histone $\mathrm{H} 3$ acetilationa. Toxicology Letters. v. 177, p. 90-96, 2008. 
Brandão, L. F. G. et al./Revista Eletrônica de Farmácia Vol 5(3), 33 - 38, 2008.

OKUDA, T. Systematics and health effects of chemically distinct tannins in medicinal plants. Phytochemistry. v. 66, p. 2012-2031, 2005.

YAO, H.; CHANG, Y.; LAN, S.; YEH, T. The Inhibitory effect of tannic acid on cytochrome P450 enzymes and NADPH-CYP reductase in rat and human liver microssomes. Food and Chemical Toxicology. v. 46, p. 645-653, 2008.

WHO - WORLD HEALTH ORGANIZATION, Quality Control Methods for Medicinal Plant Materials, Geneva, 1992. 